\title{
Use of Irradiated Polymers after Their Lifetime Period
}

\author{
David Manas ${ }^{1,2,+}$, Miroslav Manas ${ }^{1}$, Ales Mizera ${ }^{1, *(1)}$, Jan Navratil ${ }^{3}$, Martin Ovsik ${ }^{2}$ (i) , \\ Katarina Tomanova ${ }^{4}$ and Stanislav Sehnalek ${ }^{1}$ iD \\ 1 Faculty of Applied Informatics, Tomas Bata University in Zlin, CEBIA-Tech, Nad Stranemi 4511, \\ 76005 Zlin, Czech Republic; dmanas@utb.cz (D.M.); manas@utb.cz (M.M.); sehnalek@utb.cz (S.S.) \\ 2 Faculty of Technology, Tomas Bata University in Zlin, Vavreckova 275, 76001 Zlin, Czech Republic; \\ ovsik@utb.cz \\ 3 SKODA AUTO a.s., tr. Vaclava Klementa 869, 29301 Mlada Boleslav-Mlada Boleslav II, Czech Republic; \\ jan.navratil@skoda-auto.cz \\ 4 Department of Polymer Processing, Slovak University of Technology in Bratislava, Vazovova 5, \\ 81243 Bratislava, Slovakia; katarina_tomanova@stuba.sk \\ * Correspondence: mizera@utb.cz; Tel.: +420-576-035-636 \\ + This article is dedicated, in memoriam, to Assoc. Prof. David Manas.
}

Received: 16 May 2018; Accepted: 6 June 2018; Published: 9 June 2018 updates

\begin{abstract}
This article deals with the study of the utilisation of irradiated HDPE products after their end-of-life cycle. Today, polymer waste processing is a matter of evermore intensive discussion. Common thermoplastic waste recycling-especially in the case of wastes with a defined composition - is generally well-known — and frequently used. On the contrary, processing cross-linked plastics is impossible to do in the same way as with virgin thermoplastics-mainly due to the impossibility of remelting them. The possibility of using waste in the form of grit or a powder, made from cross-linked High Density PolyEthylene (rHDPEx) products, after their end-of-life cycle, as a filler for virgin Low Density PolyEthylene (LDPE) was tested in a matrix. It was found that both the mechanical behaviour and processability of new composites with an LDPE matrix, with rHDPEx as a filler, depend - to a high degree- on the amount of the filler. The composite can be processed up to $60 \%$ of the filler content. The Polymer Mixture Fluidity dropped significantly, in line with the amount of filler, while the mechanical properties, on the other hand, predominantly grew with the increasing amount of rHDPEx.
\end{abstract}

Keywords: polymer recycling; radiation cross-linking; end-of-life cycle; polymers; mechanical properties

\section{Introduction}

The plastics industry plays a very important role in the global economy. In the last few years, polymers have become one of the most important materials. Polymers are used in a wide range of applications-e.g., packaging, household applications, sport and leisure time accessories. Plastic materials play a very important role in the design of electrical and electronic products, medical applications and automotive, aircraft and aerospace industry components. In co-dependence with the growth of the plastics industry, the amount of generated waste of both types of plastic parts in the end-of-life cycle and post industrial waste phases is also increasing. Research works concerning real time prediction of some types of polyolefin or biodegradable polymer films were also carried out $[1,2]$. The quality of the waste differs from the point-of-view of its origin. Waste generated during the production process-e.g., runners and sprues from injection moulding-or off-specification products from injection moulding, extrusion, blow moulding, thermoforming and other processes are easy to identify and are usually of high quality. This declaration is correct for plastic products made from one type of polymers. Multicomponent plastic parts, or composites, mainly come from injection 
moulding or extrusion processes. The quality of the polymers derived from end-of-life products depends on the way the waste is collected, and could lead to problems. This differs from country to country. End-of-life products can be collected separately or together with other waste [3]. For these reasons, this waste could lead to mixed plastics of unknown composition and could also be potentially contaminated by organic or inorganic fractions [4]. This makes the waste processing/recycling process much more complicated. Today, there is a huge amount of plastic waste to dispose of, and only about $30 \%$ of this is effectively recycled, while roughly the same amount is landfilled. The rest is used for energy recovery [5].

The reduction of plastic waste and the discovery of effective ways to recycle plastics is the greatest challenge for scientists, producers and users of polymer parts in the future. Today, the most common plastic waste processing method is mechanical recycling, which includes various steps leading to the conversion of the waste into a useful material. These steps cover the collection, sorting, washing/cleaning, and grinding of the waste. The crushed material can be used directly as an addition to a virgin polymer and could be re-granulated in the next possible step [5-11]. These steps may occur in different order, multiple times, or not at all, depending on the origins and composition of the waste. In the simplest case, it will be in the form of runners and sprues from injection-moulding or waste from its beginning to its production by extrusion, where the origin and type of waste is clear, and this material is usually clean. In the case of mixed plastics, the process is much more complex and covers additional steps-e.g., sorting the waste according to the type and colour of the polymers, and steps leading to organic and inorganic contaminants being removed [4]. Various principles and methods are used for the sorting step including Fourier-Transform Near-InfraRed spectroscopy (FT-NIR), Optical Colour Recognition, Electrostatic Separation, Flotation, Magnetic Separation, X-ray Detection, or manual sorting [12-15]. During the re-granulation of recycled materials process, melting filtration is used to remove non-melting components-e.g., wood, paper, rubber particles [16], or polymers with higher melting temperatures [17]. Mechanical/material recycling represents a way of processing waste into new products without any changes to the macromolecular structure. Usually, this type of new product has very good properties, possibly even approaching those of the original item. Usually, the reground material/waste is mixed with virgin resin. Another method is chemical recycling, which refers to the decomposition of macromolecular structures in order to generate low molecular-weight components such as monomers for their utilisation in polymeric materials, synthetic gases, mixtures of liquids for the petrochemical industry, or as fuels and so on. The chemical recycling process includes many techniques-including chemolysis, pyrolysis, fluid catalic cracking, hydrogen technologies, or gasification [18-20]. Material recycling with the remelting of a new material obtained from a waste is suitable for the thermoplastics industry. The remelting process is not applicable for polymers modified by irradiation cross-linking. Because of the ever-growing knowledge of polymer property changes after irradiation, the new technology of radiation cross-linking is applied in the production of a huge number of products [21-23].

Over the last few decades, the industrial use of radiation cross-linking for standard as well as engineering polymers has increased rapidly. The cross-linking process enables one to change the properties of plastics, and especially, to improve their mechanical, chemical and thermal properties [23-26]. Using the irradiation cross-linking technology, it is possible to prepare plastics with properties that accord to consumer requirements, i.e., so-called "tailored plastics". Some plastics, e.g., polyethylene (PE), can be cross-linked without any need of cross-linking agents. Other polymers, polyamides for instance, require the addition of additives prior to processing to enable the cross-linking reaction during the radiation process [21,22]. Linked with the increasing production of cross-linked plastic products, the production of waste rapidly increases. Up until today, there still is no efficient technology of cross-linked plastic waste processing to its disposal. Despite improvement in their properties, radiation cross-linked thermoplastic materials lose their natural ability of being re-melted repeatedly, due to the formation of networks [25,27-32]. 
This article describes one of the possible ways of processing recycled cross-linked High Density Polyethylene (rHDPEx), originally used for the production of underfloor heating systems. There is a huge amount of waste from this production to dispose of, and millions of kilometres of heating pipes are installed in buildings. It is therefore necessary to think about what will be done with this material/processing waste or waste at the end of such productts' lifetimes.

\section{Materials and Methods}

Crushed cross-linked rHDPEx from underfloor heating pipes as the filler added to the LDPE matrix was used in this study. Granulate of virgin LDPE as a matrix, and recycled irradiated rHDPEx, were used for the preparation of two types of mixtures.

\subsection{Material}

The wide availability of rHDPEx was the main reason for the use of this polymer in the research presented herein. This material was supplied in the form of heating pipes used for underfloor heating systems. The pipes were crushed using the low-speed knife mill, type MASKIN AB RAPIS S-33010, screen size $5 \mathrm{~mm}$ and ground using the toothed disc mill, type Condux. To obtain crushed or powdered material for further processing, the particles with dimension higher than $1 \mathrm{~mm}$ were separated from the powder using screen $1 \mathrm{~mm}$. The pipes were originally irradiated by beta (electron) radiation, with an energy of $10 \mathrm{MeV}$, and irradiation dose of $165 \mathrm{kGy}$. Low Density PolyEthylene (LDPE-780E, Dow Chemical Company, Midland, MI, USA) was chosen as the polymer matrix regarding their ease of processability, low price and wide availability. LDPE granulate was used as the polymer matrix and rHDPEx in grit or powder states were used as the filler.

\subsection{Irradiation}

Irradiation of used HDPE pipes originally determined for use in underfloor heating systems was originally carried out at the premises of BGS Beta-Gama-Servise Company (Wiehl, Germany), Germany. Electron beam radiation, with the dose of $165 \mathrm{kGy}$, and energy of $10 \mathrm{MeV}$, was used for their irradiation. The cross-linking of used HDPE was realized without the use of a cross-linking agent. Gel Content Measurement and a Dosimeter were used to determine and find proof of correctness. The correct radiation dose was checked by a Nylon FTN 60-00 dosimeter; and the analysis using a Genessis (Goleta, CA, USA) 5 spectrophotometer in correspondence with the ASTM 51261 standard [33]. Gel content was measured according to the ASTM D7567 standard [34], which is determined by means of solvent extraction with xylene. The dose of $165 \mathrm{kGy}$ corresponds to $60 \%$ gel content.

\subsection{Specimen Preparation}

From crushed and powdered material, two types of mixtures, which differ from each other by filler state (grit or powder, rHDPEx), were prepared: Mixture A (LDPE granulate + rHDPEx grit) and Mixture B (LDPE granulate + rHDPEx powder). Crushed (particle size of 1-5 mm) or powdered rHDPEx was mixed together with virgin LDPE granulate in a laboratory fluid mixer. A size analysis was performed using Retsch AS 200 Basic equipment (Figure 1) for determination of particle size distribution. Figure 1 shows that dimensions of $68 \%$ particles are in interval $0.5-1.0 \mathrm{~mm}$ and only less than $0.05 \%$ particles are smaller than $0.09 \mathrm{~mm}$. From this mixture, in concentrations ranging 10-60 wt. \% of rHDPEx in virgin LDPE, specimens according to the ISO 527 standard [35] were prepared by injection moulding using an Arburg Allrounder $470 \mathrm{H}$ injection moulding machine type 1 , specimens for Impact test and type 1A, specimens for Tensile test. Dimensions of specimens are in Figure 2 and the processing conditions are given in Table 1.

Ten samples were prepared for each testing method and statistical evaluation was realized in programmes TestXpert II (V3.31, Zwick/Roell, Ulm, Germany), MS Excel 2016 (Microsoft, Redmond, WA, USA) and MiniTab (v16, State, College, PA, USA). In all figures, arithmetic mean and standard deviation are used. 
Table 1. Injection moulding processing parameters.

\begin{tabular}{lcc}
\hline \multicolumn{3}{c}{ ARBURG ALLROUNDER 470H } \\
\hline Injection Velocity & 60 & $\mathrm{~mm} \mathrm{~s}^{-1}$ \\
Injection Pressure & $45\left(55^{1}\right)$ & $\mathrm{MPa}$ \\
Cooling Time & 30 & $\mathrm{~S}$ \\
Mould Temperature & 40 & ${ }^{\circ} \mathrm{C}$ \\
Holding Time & 10 & $\mathrm{~S}$ \\
Holding Pressure & $40\left(55^{1}\right)$ & $\mathrm{MPa}$ \\
\hline \multicolumn{4}{c}{ Temperature of Plasticizing Unit Zones } \\
\hline Temperature under the Hopper & 40 & ${ }^{\circ} \mathrm{C}$ \\
Temperature Zone 1 & 135 & ${ }^{\circ} \mathrm{C}$ \\
Temperature Zone 2 & 140 & ${ }^{\circ} \mathrm{C}$ \\
Temperature Zone 3 & 150 & ${ }^{\circ} \mathrm{C}$ \\
Temperature Zone 4 & 160 & ${ }^{\circ} \mathrm{C}$ \\
Temperature Zone 5 & 180 & ${ }^{\circ} \mathrm{C}$ \\
\hline
\end{tabular}

${ }^{1}$ used at the highest concentration of filler $(60 \mathrm{wt} . \%)$.

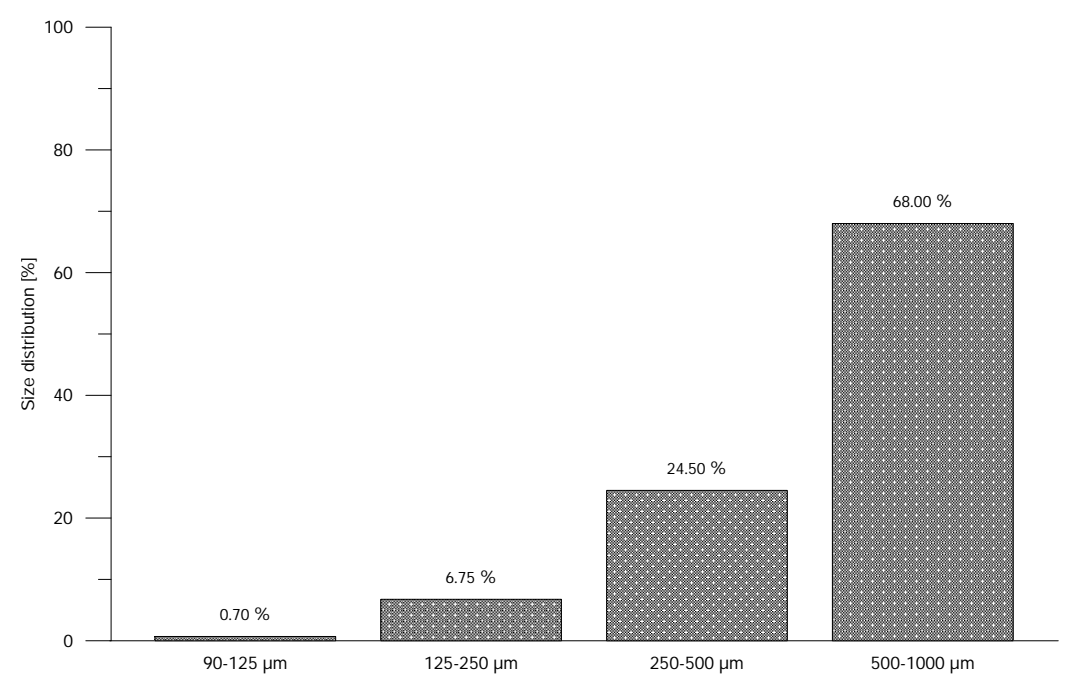

Figure 1. Powder size distribution.
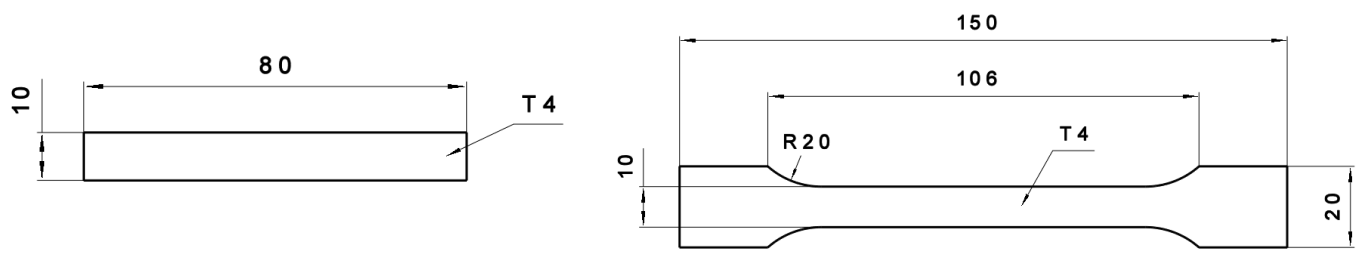

Figure 2. Dimensions of testing specimen: type 1 (left) and type $1 \mathrm{~A}$ (right).

\subsection{Melt Flow Measurement}

A Type LMI 4003Dynisco Kayeness Melt-flow Indexer was used to measure the Melt Flow Index (MFI). The measurements were performed according to ISO 1133 standard [36], and a load of $2.16 \mathrm{~kg}$ at the temperature of $190^{\circ} \mathrm{C}$. 


\subsection{Polymer Mixture Fluidity}

A Modified Spiral Test was performed using a spiral cavity mould [37], with a spiral length of $2000 \mathrm{~mm}$; the shape of the cavity is rectangular, with the dimensions of $6 \mathrm{~mm} \times 1 \mathrm{~mm}$ (Figure 3). Arburg Allrounder $470 \mathrm{H}$ injection moulding machine (Loßburg, Germany) was used for testing purposes.

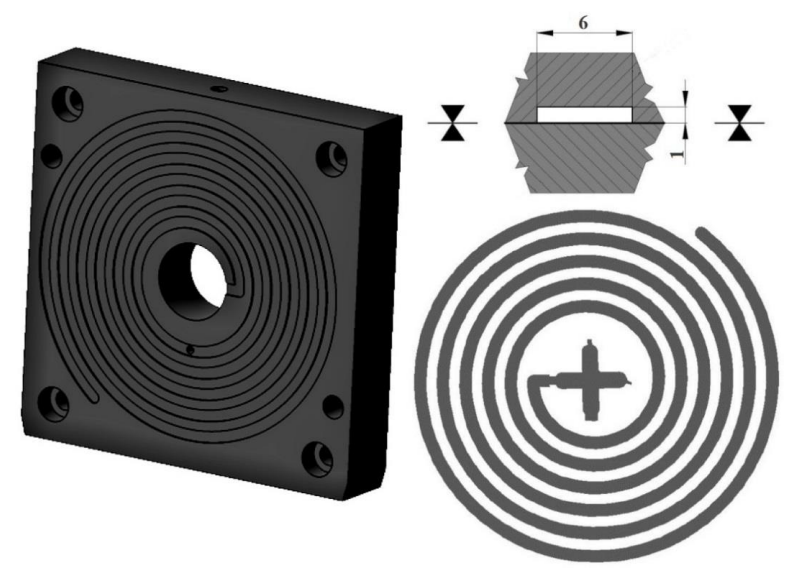

Figure 3. Spiral cavity mould.

\subsection{Tensile Test}

A ZWICK 1456 tensile machine (Ulm, Germany) was used for the estimation of tensile behaviour. Measurements were carried out according to the ISO 527 standard [35] at ambient $\left(23^{\circ} \mathrm{C}\right)$ and elevated $\left(80^{\circ} \mathrm{C}\right)$ temperatures with crosshead speed of $50 \mathrm{~mm} / \mathrm{min}$. The E-modulus, ultimate tensile strength and strain were all evaluated from these measurements. Conditioning was taken for five days at temperature of $23^{\circ} \mathrm{C}$ and relative humidity of $50 \%$.

\subsection{Shore D Hardness (ShD)}

An OMAG AFFRI ART 13 Shore D hardness tester (Varese, Italy) was used for hardness testing in accordance with the ISO 868 standard [38], therefore holding time was $15 \mathrm{~s}$.

\subsection{Micro Indentation}

Micro-indentation tests were performed using a CSM Instruments Micro Combi tester (Needham, MA, USA), according to the ISO 14577 standard [39]. A Vickers type indentor with a diamond tip was used, with a maximal load of $1 \mathrm{~N}$; loading and unloading rate $2 \mathrm{~N} / \mathrm{min}$; and holding time $90 \mathrm{~s}$.

\subsection{Impact Test}

The Charpy impact test was carried out on Zwick HIT50P equipment (Ulm, Germany) at an ambient temperature of $23^{\circ} \mathrm{C}$ according to the ISO 179 standard [40]. In this impact hammer test, $50 \mathrm{~J}$ of potential energy was used for research purposes. Fifteen samples were tested (Figure 2), and their impact toughness values were evaluated in the TestXpert II (ZWICK, Ulm, Germany), MS Excel (Redmond, Washington, USA) and MiniTab 16 (Minitab Ltd., Brandon Court Unit, Coventry, UNITED KINGDOM) programmes. Arithmetic mean and standard deviation were used as the statistical parameters in this measurement process. Conditioning was taken for five days at temperature of $23^{\circ} \mathrm{C}$ and relative humidity of $50 \%$.

\subsection{Structural Analysis}

A LEICA RM2255 microtome (Eisfeld, Germany) was used for the preparation of samples (thickness of $35 \mu \mathrm{m}$ ) and an OLYMPUS BX41 microscope (Tokyo, Japan) was used for the structural 
analysis. Equally, the structure was investigated on the fracture area with nitrogen-cooled bodies using a JEOL 7500F scanning electron microscope (Tokyo, Japan).

\section{Results and Discussion}

Tensile testing was chosen because it provides the most complex overview of the mechanical properties of a tested material. For better comparison of the measured data, the values of virgin LDPE are also shown in the figures. The Elastic Modulus of Mixture A at room temperature already begins to show improvements by the addition of only $10 \%$ of rHDPEx. Adding more filler causes a dramatic hike-up to $452 \mathrm{MPa}$ at the highest concentration (60\%)—which represents a nearly double higher elastic modulus in comparison with virgin LDPE. It is possible to observe the same tendency in the elastic modulus results of Mixture B (Figure 4). Differences in the elastic modulus values-as measured for both mixtures, are insignificant and lie within the measurement error limits. Roughly the same increase (i.e., double) of the elastic modulus was found by tests at the elevated temperature of $80^{\circ} \mathrm{C}$ (Figure 5), at the highest concentration point of the filler.

Ultimate Tensile Strength increases continually with the amount of filler content and, at the concentration of $60 \%$ of rHDPEx in the LDPE matrix, the increase is about $40 \%$ (Figure 6). That correlates very well with the tendency of the increase of the elastic modulus at ambient conditions. No significant differences in the comparison of Mixtures A and B were found. The differences of the measured values are within the error measurement range. At elevated temperatures, the ultimate tensile strength in Mixture A-due to the addition of 10-40\% of filler-decreases slightly, and, at the maximum filler content $(60 \%)$, the ultimate tensile strength is $12 \%$ higher than that of the virgin LDPE in the case of Mixture A. With regard to the measurement error, composite Mixture A-containing a $10-50 \%$ filler content-has the same Ultimate Tensile Strength as the LDPE matrix. A slight increase is recorded at a dose of $60 \mathrm{wt}$. \% fillers. Mixture B shows a gradual improvement in tensile strength, and, at the highest rHDPEx concentration, it is $34 \%$ higher than that of LDPE (Figure 7).

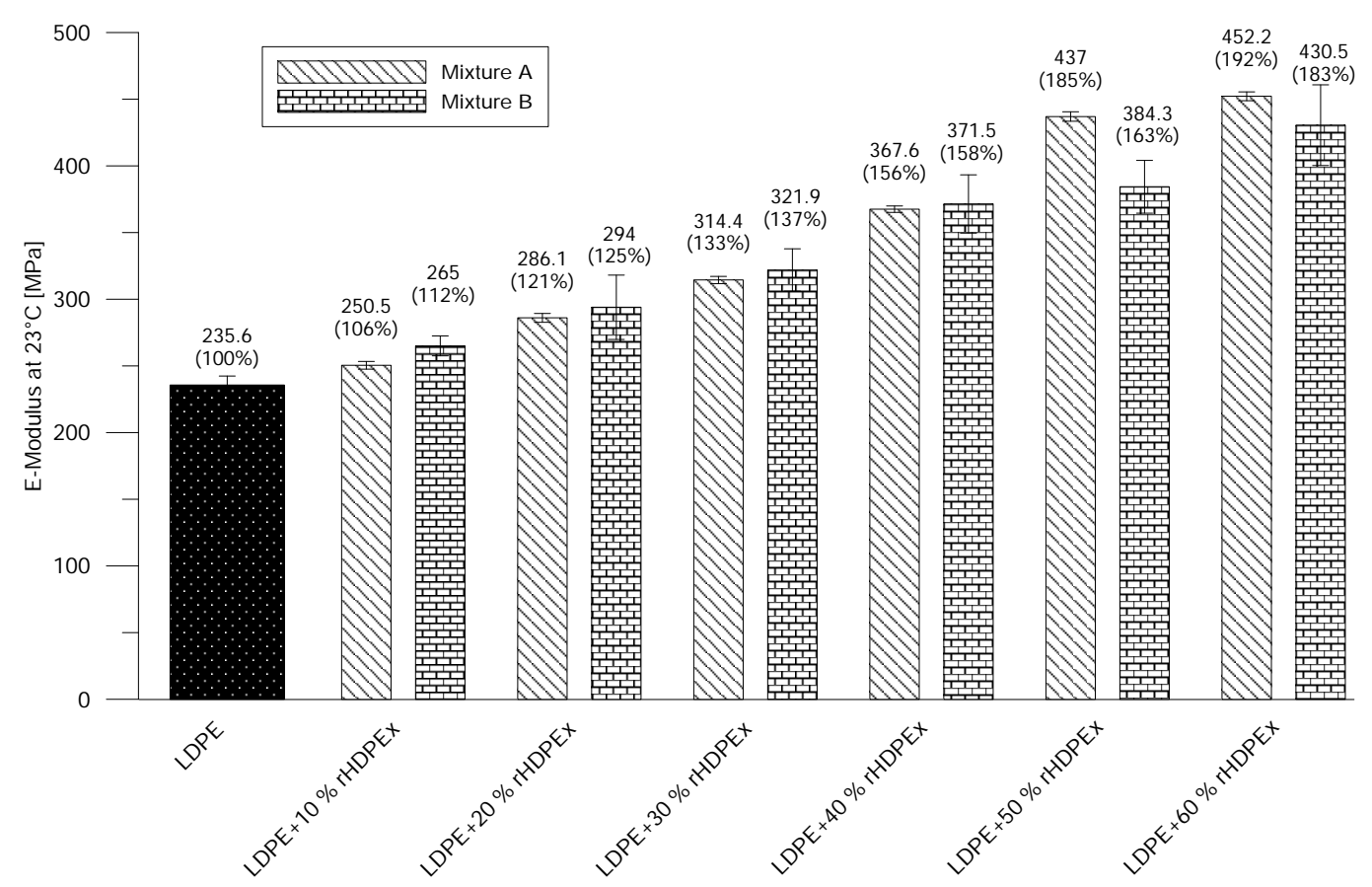

Figure 4. E-modulus at ambient temperature-Mixtures A and B. 


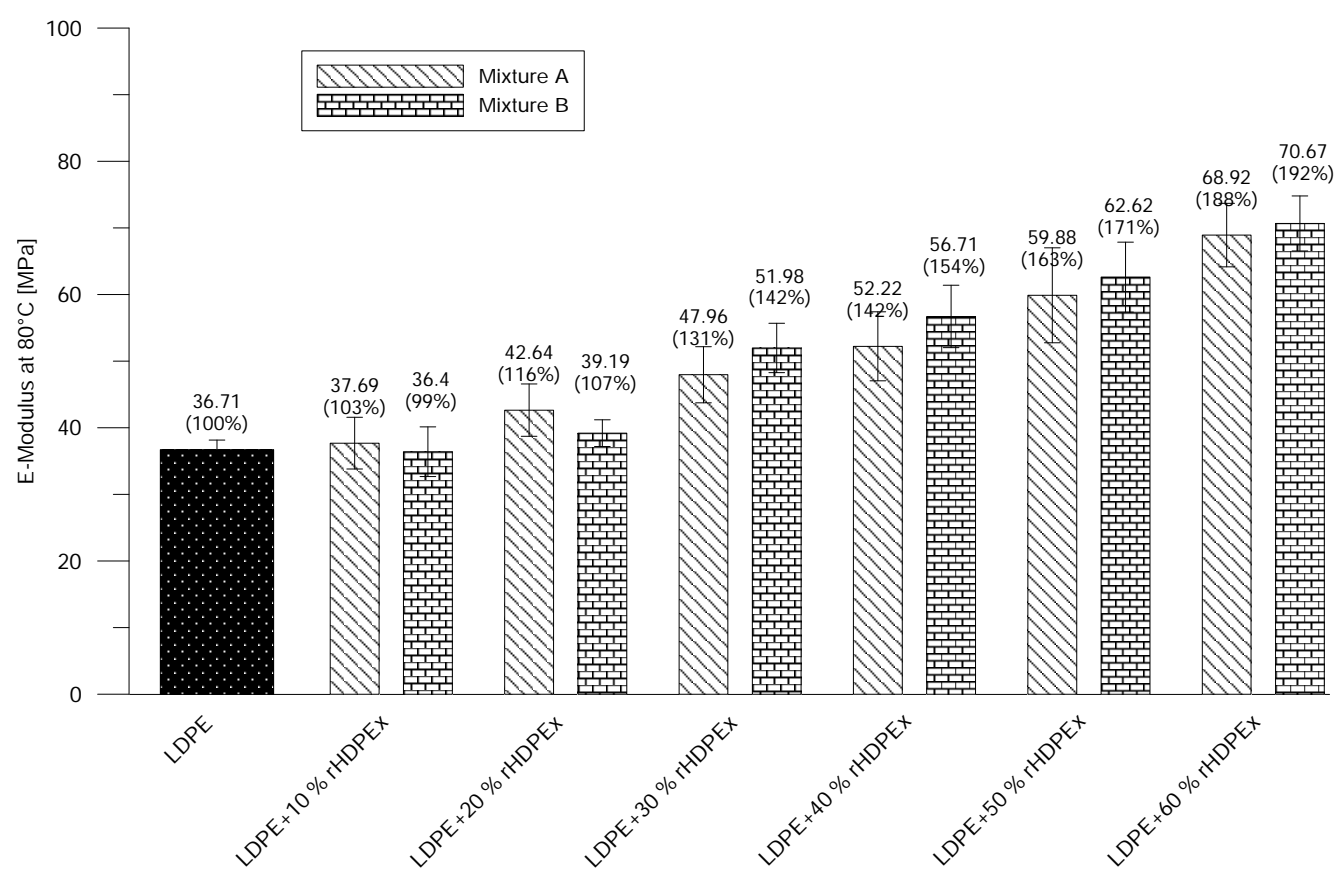

Figure 5. E-modulus at elevated temperature-Mixtures A and B.

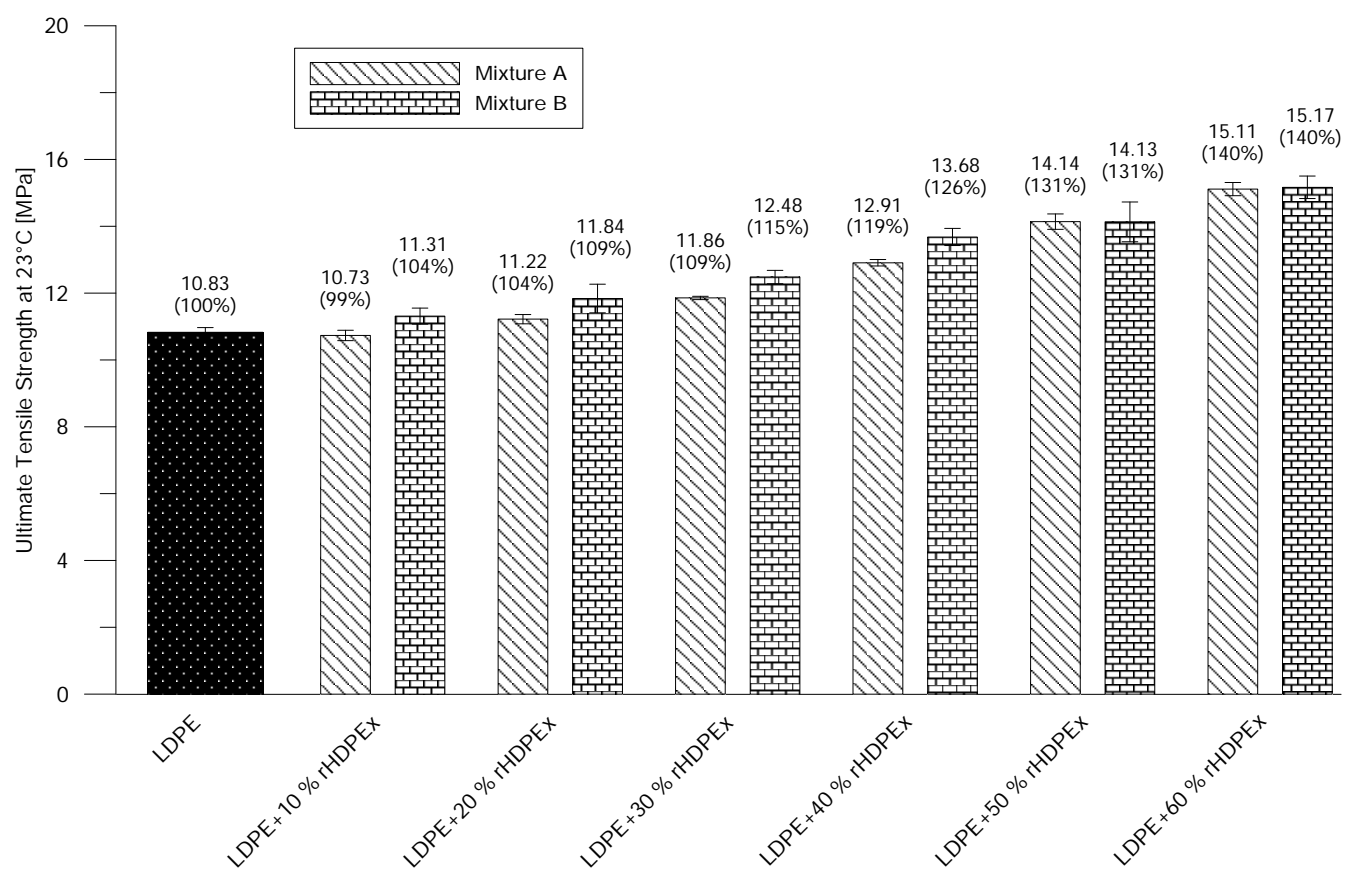

Figure 6. Ultimate tensile strength at ambient temperature-Mixtures A and B.

A dramatic drop in strain at break was observed-even at the lowest filling concentration (Figure 8). The addition of $10 \%$ rHDPEx as a filler resulted in a significant decrease of strain to $60 \%$ Mixture A, and higher concentrations of filler in the LDPE matrix caused gradual decreases in the strain value. The difference at the highest concentration of the filler represents a decrease of strain of about $82 \%$ (Mixture A) or $69 \%$ (Mixture B). However, the drop in strain values for B is significantly slower in comparison to Mixture A. It is possible to observe the same tendency by means of strain measurement at the elevated $\left(80^{\circ} \mathrm{C}\right)$ temperature (Figure 9$)$. Just as with normal temperature test results, a more pronounced decrease in Strains in Mixture A, as compared to Mixture B, can be 
observed, even at elevated temperatures. This corresponds very well with the increase of E-modulus and tensile strength - and attests to the influence of rHDPEx as a filler, both from the point of view of filler content and particles size.

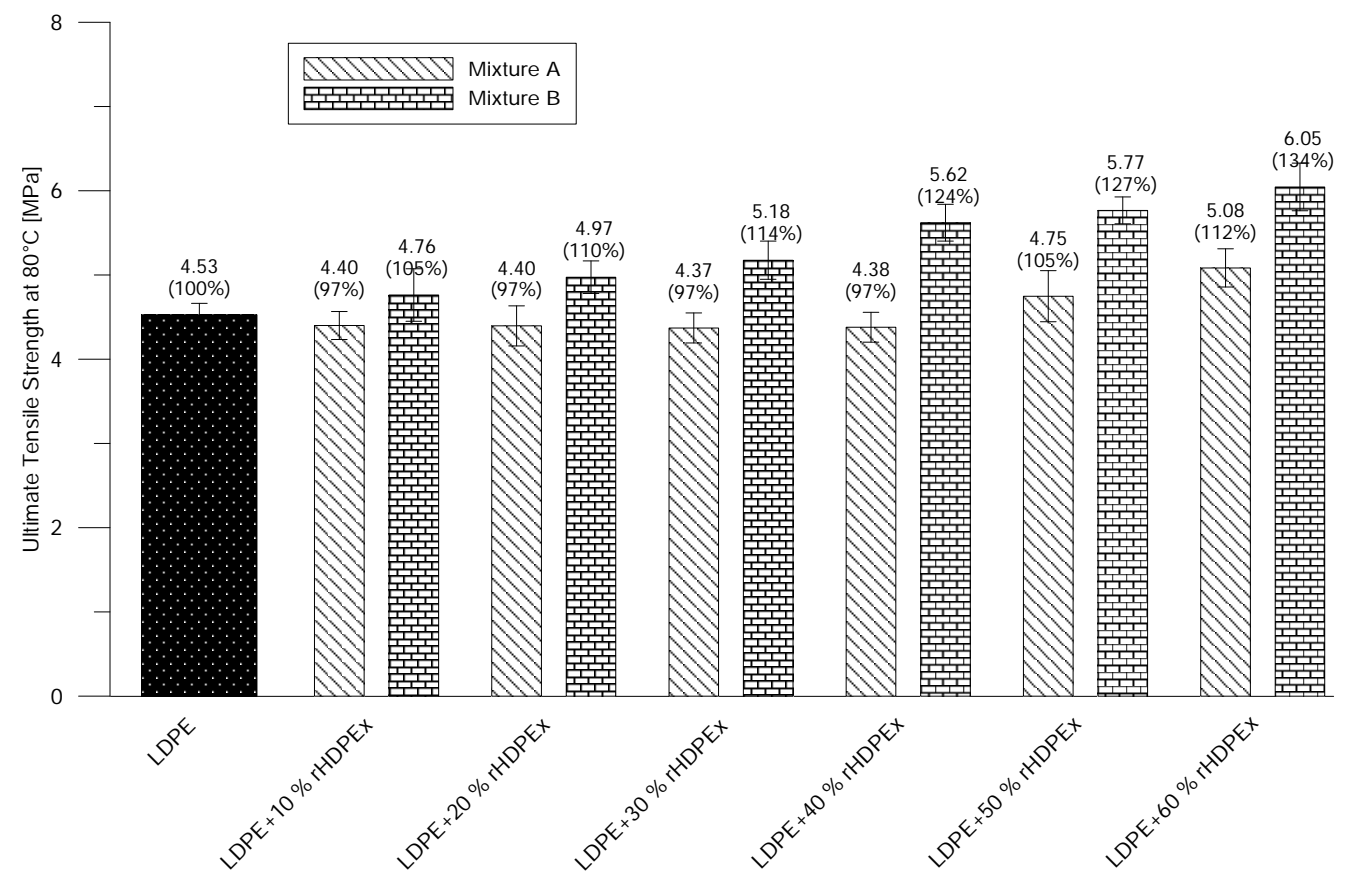

Figure 7. Ultimate tensile strength at elevated temperature-Mixtures A and B.

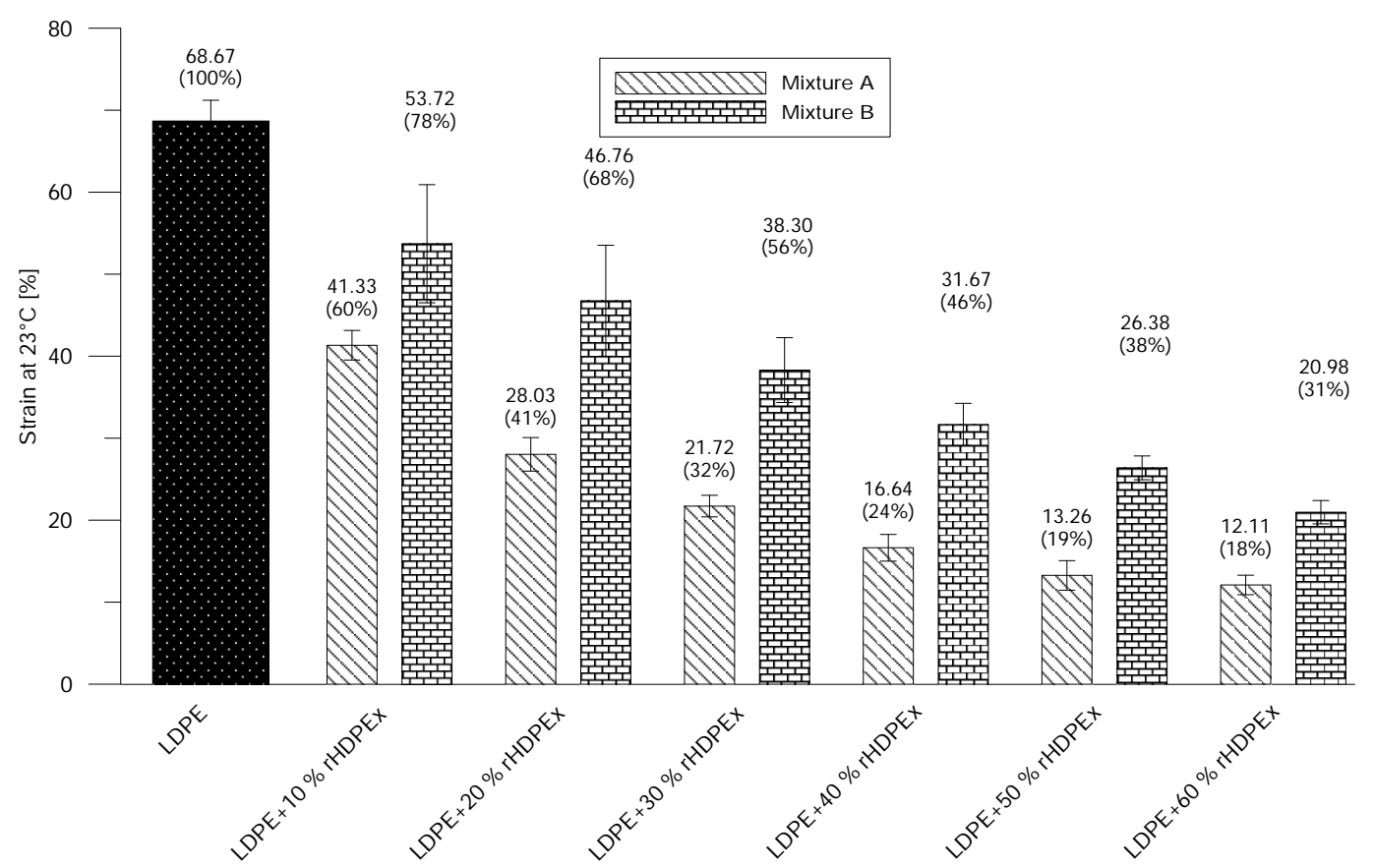

Figure 8. Strain at ambient temperature-Mixtures A and B. 


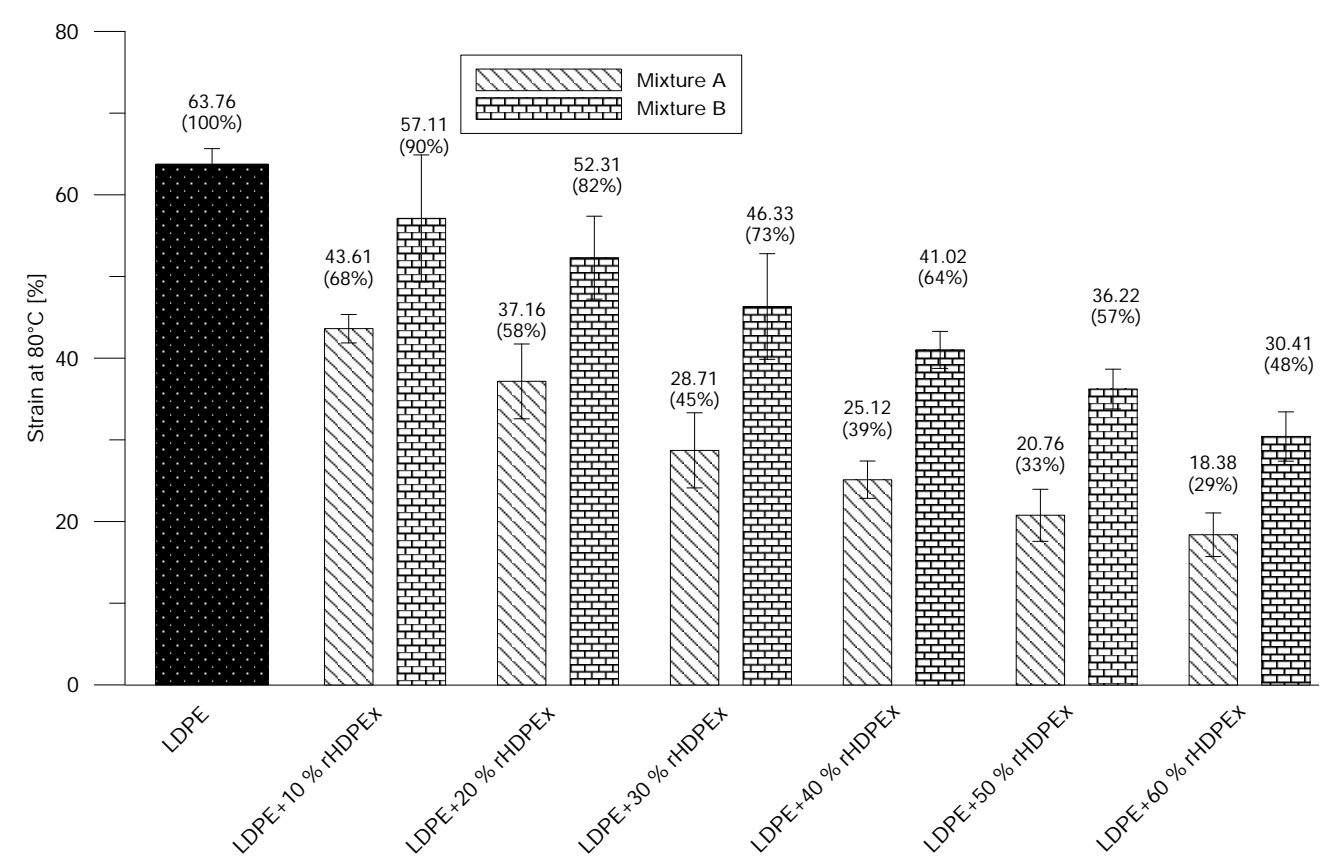

Figure 9. Strain at elevated temperature-Mixtures A and B.

Shore D Hardness is in line with the increase of rHDPEx in the LDPE matrix. The ShD hardness continually rises to nearly $20 \%$ above the hardness of virgin LDPE with the highest filler content. There is only an insignificant difference in hardness when comparing Mixtures A and B (Figure 10); the measured values mainly lay within the measurement error interval. The micro-hardness of the tested material - represented by the indentation hardness $H_{I T}$-shows only very low changes with the rising level of the filler/grit concentration in the case of Mixture A. On the other hand, increasing content of the rHDPEx filler in the form of powder (Mixture B) causes significant changes in the indentation hardness-especially for filler batches of 30-60 wt. \%. At the concentration level of $60 \mathrm{wt}$. \% of rHDPEx powder, the indentation hardness is $62 \%$ higher-as compared to virgin LDPE (Figure 11).

The impact properties of Mixtures A and B are strongly influenced by the concentration of the rHDPEx filler. By the addition of $10 \%$ of filler in Mixture A, the changes in Charpy Notched Impact Strength are negligible, but further increases led to considerable decreases in the impact properties. The difference in the impact strength of virgin LDPE and a composite with the addition of $60 \mathrm{wt} . \%$ rHDPEx grit is $54 \%$. The addition of rHDPEx filler in the form of a powder (Mixture B) causes significant changes in impact toughness. This is already detectable from the smallest content of the powdered filler. At the rHDPEx powder concentration of $10 \%$, the impact toughness dropped by up to $45 \%$ of the value of the virgin LDPE. With further increases in filler content, impact toughness continually decreased, down to 17\% that of the virgin LDPE (Figure 12). From the measured values, it follows that the Impact properties of both mixtures are affected by the filler content and the size of the filler particles.

The basic processing parameter is represented by the MFI, which is a standard polymer flow behaviour test. Due to the crushed particles' dimensions-and the impossibility of melting rHDPEx-it was impossible to make MFI measurements for Mixture A (LDPE + rHDPEx grit), so measurement was performed only for Mixture B. With an increasing dose of rHDPEx, the viscosity of Mixture B melts, with a MFI decrease to a minimum at a filler content of $60 \mathrm{wt}$. \% (Figure 13). The melt flow gradually decreases in line with increases in the rHDPEx content. A Modified Spiral Test was performed to assess the melt flow of both mixtures. An injection mould was used (Figure 3). The spirals resulting from this test are depicted in Figure 14. This spiral fluidity test most closely simulates the real processing conditions. A huge drop in the mixture melt fluidity can be seen in Figure 15, when comparing virgin 
LDPE and LDPE with $60 \%$ of recycled irradiated HDPE (rHDPEx). The viscosity of this composite increases with the filler content, and there is no possibility to add more than $60 \%$ of filler (rHDPEx) to be processed. Already addition $10 \mathrm{wt}$ \% of rHDPEx (Mixture A) causes drop of length of composite melt flow of $24 \%$ with subsequent slow decrease of fluidity with the filler content up to $45 \%$, in the case of the highest filler content. In the case of Mixture B, $10 \mathrm{wt}$. \% filler content causes no change of fluidity. Despite the relatively large difference in the length of melting of Mixtures A and B at low filler concentrations (10-30 wt. \%), the final length of the spiral (as measured at the maximum concentration of rHDPEx), is comparable.

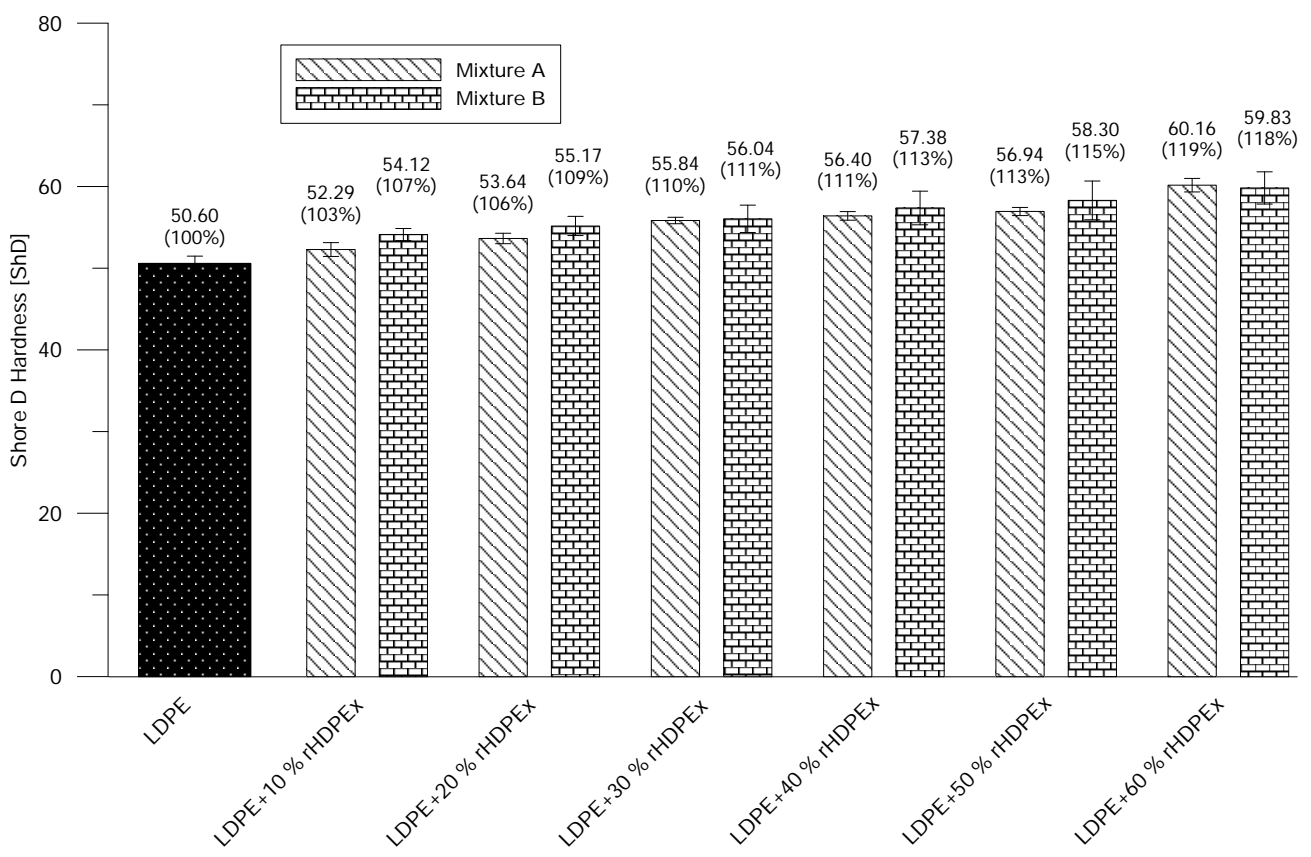

Figure 10. Shore D hardness-Mixtures A and B.

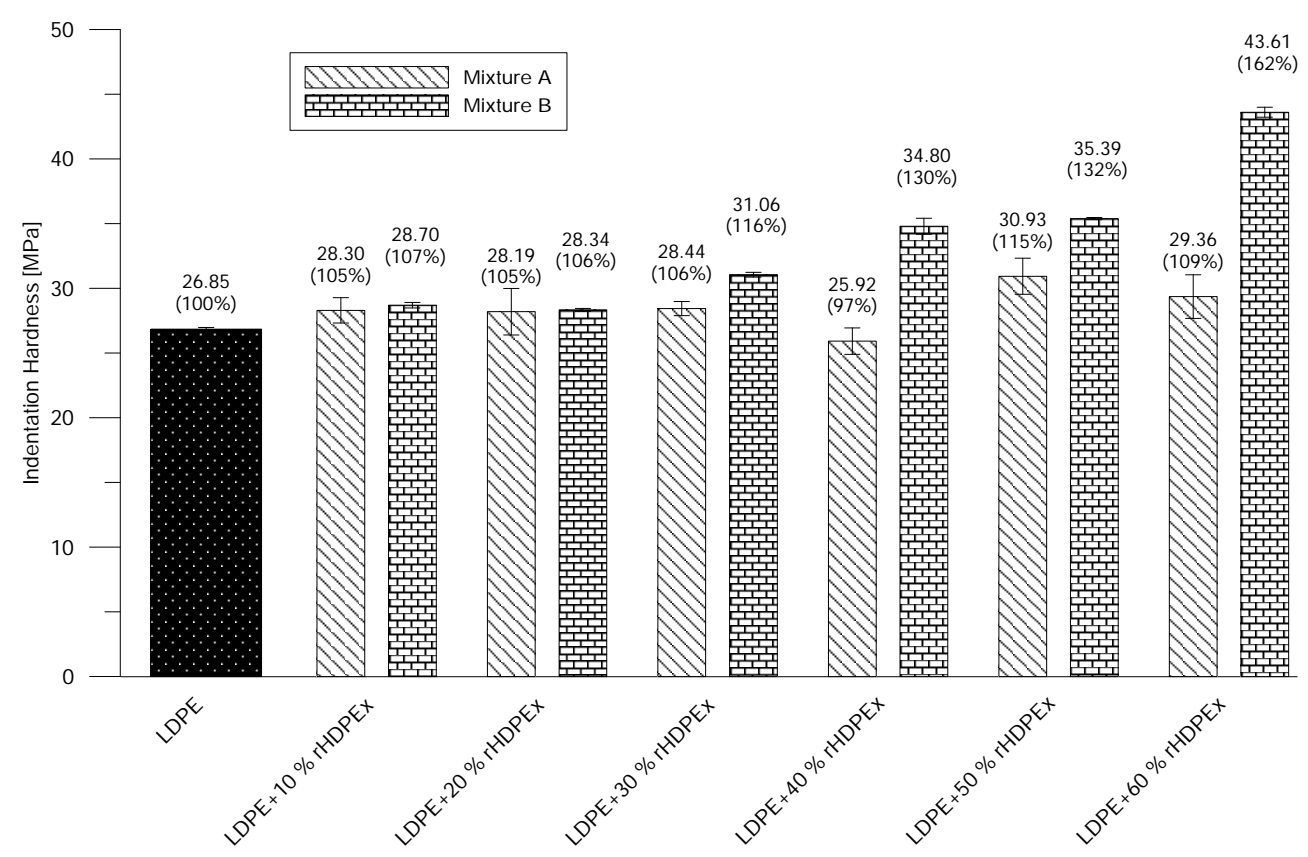

Figure 11. Micro hardness testing-Mixtures A and B. 


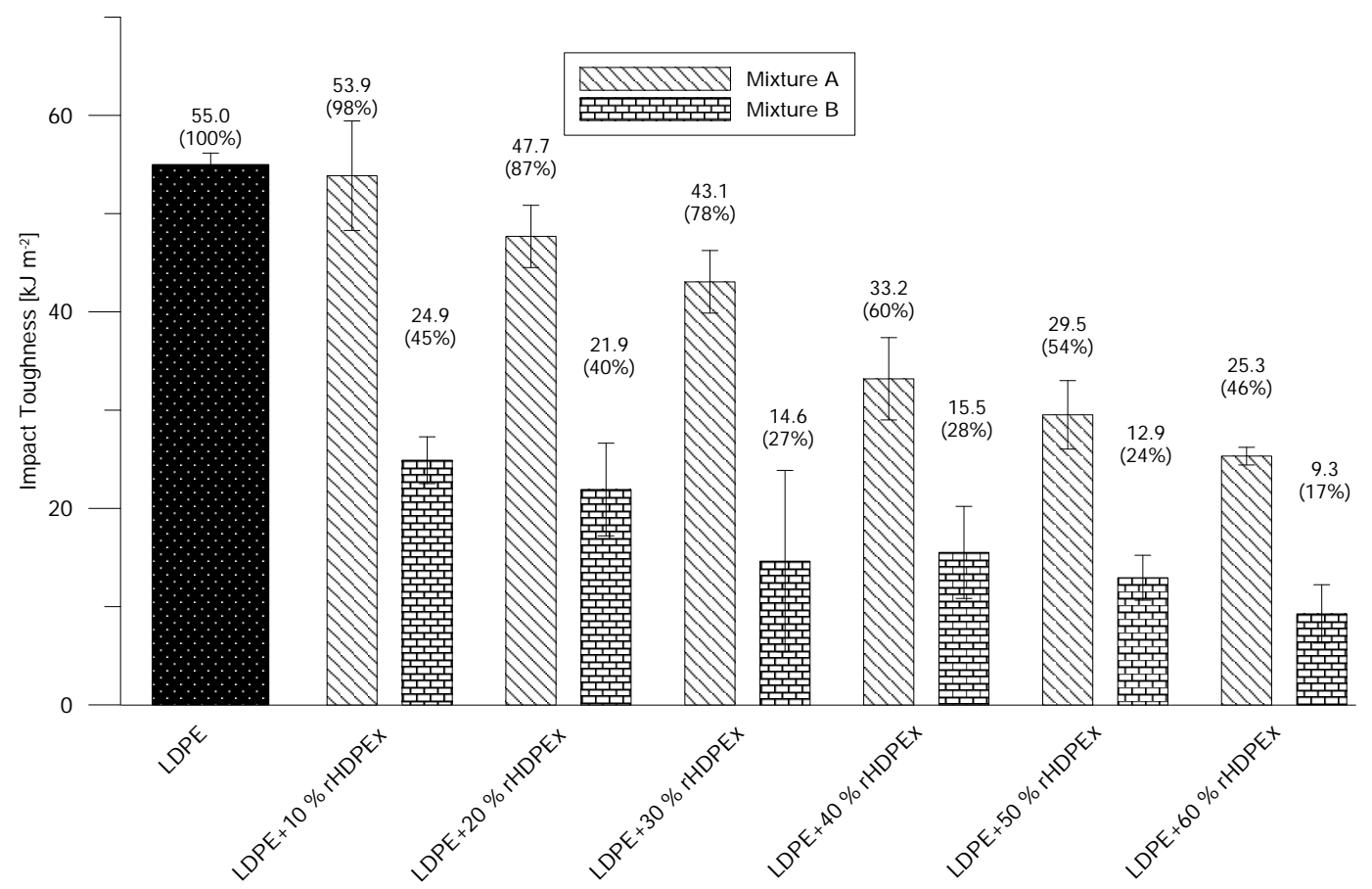

Figure 12. Impact toughness-Mixtures A and B.

Although the MFI results and the Modified Spiral Test cannot be fully compared, both tests showed that the content and particle size of the filler significantly affect the flow properties of the LDPE + rHDPEx mixtures.

To be able to evaluate the structure of the mixtures, Microtome Cuts method and SEM Fracture Microscopy (Figure 16) were used to show the characteristic fracture structures of the LDPE and HDPEx mixtures. For the structure of both tested mixtures (Figure 17), large domains of rHDPEx in the LDPE matrix are characterised by very good adhesion characteristics of the two components, without any evidence of their separation. This tendency is very clearly observed when using the microtome cuts method, where the distinct interfaces between the matrix and the filler particles are clearly visible.

It is visible from the structure of the mixtures, as shown in Figures 18 and 19, that the adhesion between the matrix (LDPE) and the filler is very good and strong. The visible interface between the LDPE matrix and rHDPEx particles attests to the fact that the rHDPEx has a similar behaviour to filler. These findings correspond very well to the measured mechanical properties values. It is possible to say that irradiation of HDPE might also help to strengthen adhesion and overcome the problematic miscibility of HDPE and LDPE. Generally speaking, the basic purpose of the filling is to increase the bulk of the polymer and to improve its desired properties, at low cost. The utilization of recycled irradiated material as filler (in our study, rHDPEx), is a very good idea, and a successful step. Further research work being realized at this time shows that the principle discussed in this article could also be successfully used for processing other irradiated polymers that represent a big problem today. The principle itself is very simple, and the results described in this paper could bring added-value in the processability of this waste into a material with improved properties-mainly its mechanical properties. Through the appropriate blending of the mixtures, it is possible to modify the properties of the matrix (LDPE) to a relatively wide extent, to suit specific requirements (so-called "tailor-made" materials). 
Results presented in this article show that there is potential to use rHDPEx as a filler up to $60 \mathrm{wt}$ \%. Mechanical properties of the mixtures are influenced by the content of the fillers: use of rHDPEx brings improvement of E-moduli, Tensile strength, shore D, and micro-hardness to Mixtures $\mathrm{A}$ and $\mathrm{B}$ when compared with virgin LDPE, while the impact toughness, strain and fluidity all show decreases. Flow properties are also influenced by the size of rHDPEx particles. In Figure 15, it follows that even $10 \mathrm{wt}$. \% of grit content in Mixture A causes a drop in fluidity of about $24 \%$ (and $34 \%$ with a filler content of $20 \mathrm{wt}$. \%), while in Mixture B $10 \mathrm{wt}$. \% of powdered rHDPEx brings no changes in fluidity and a content of $20 \mathrm{wt}$. \%, causes a decrease of only $7 \%$. The mechanical and flow properties of the tested mixtures are affected-not only by the filler content, but also has a significant effect on the size of filler particles, which depends on the ratio of the contact areas of the filler particles and their volume.

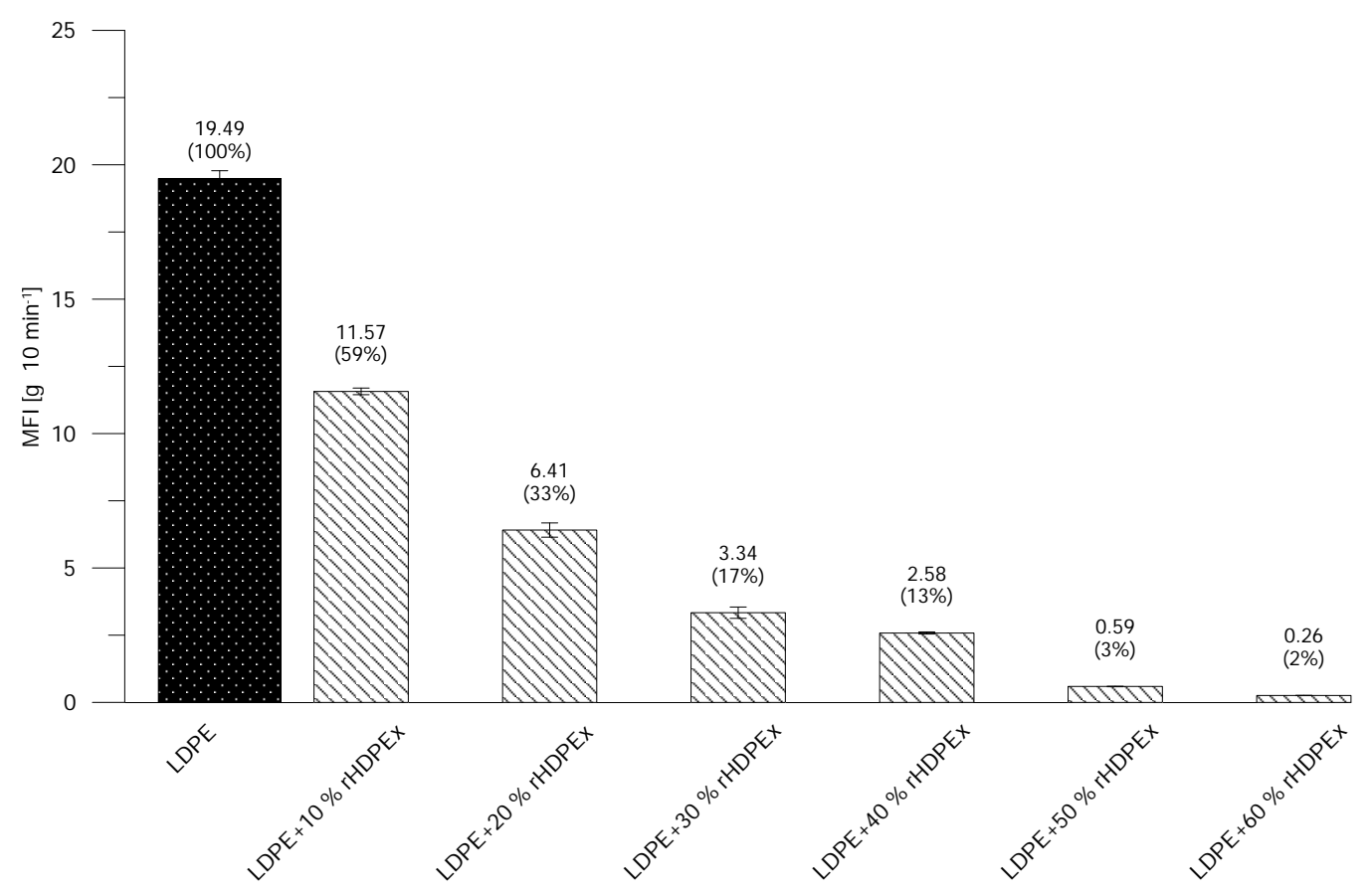

Figure 13. MFI-Mixture B.

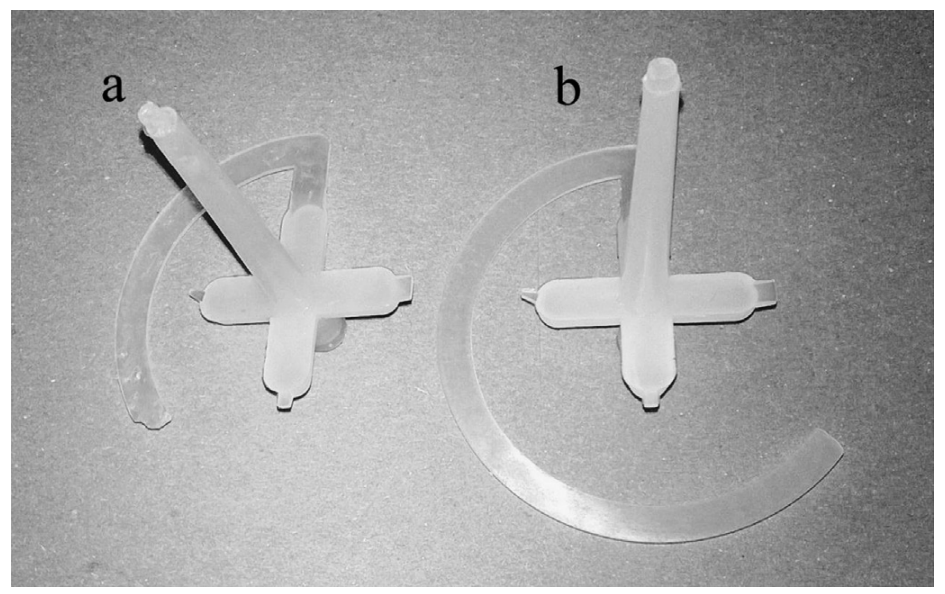

Figure 14. Resulting spirals: (a) LDPE + 60\% rHDPEx (Mixtures A); and (b) LDPE. 


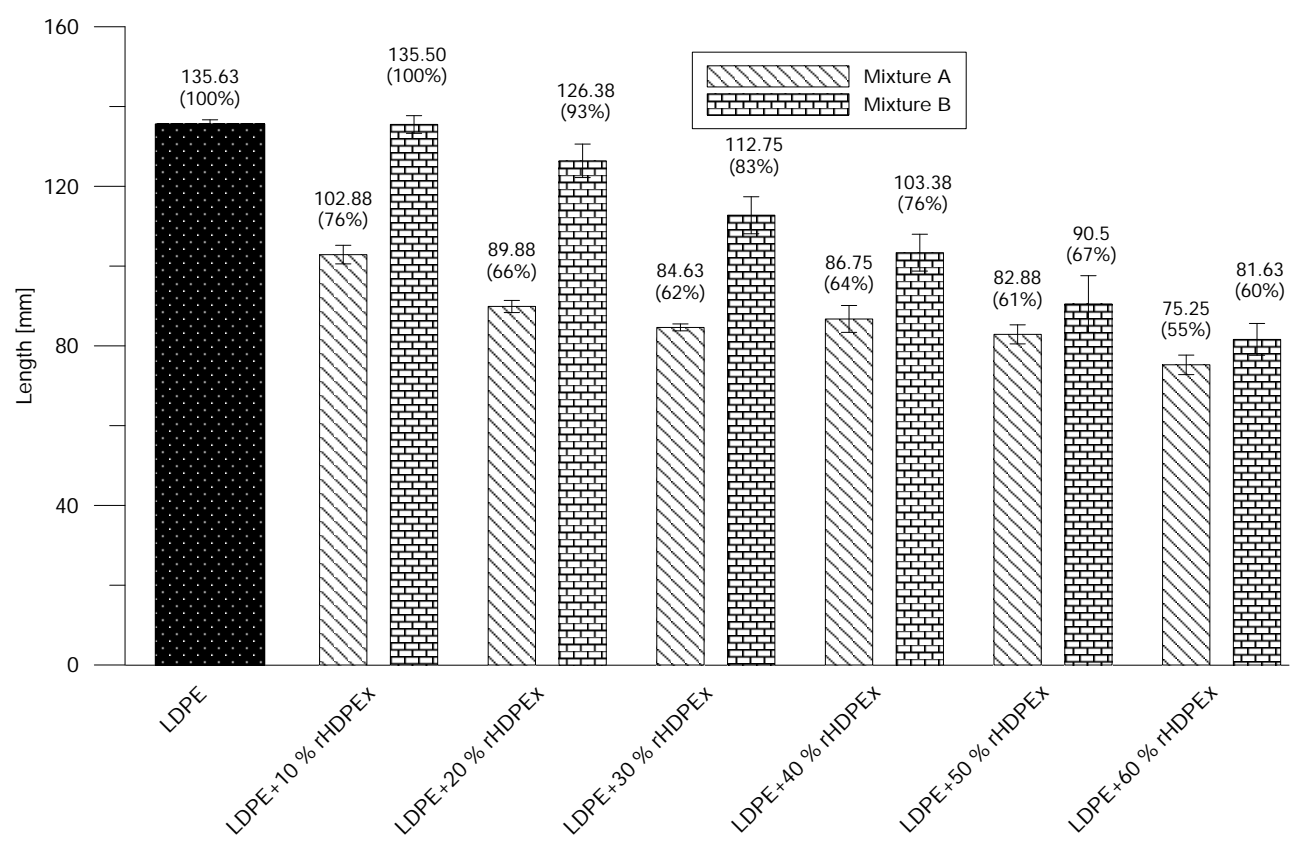

Figure 15. Polymer fluidity comparison-Mixtures A and B.
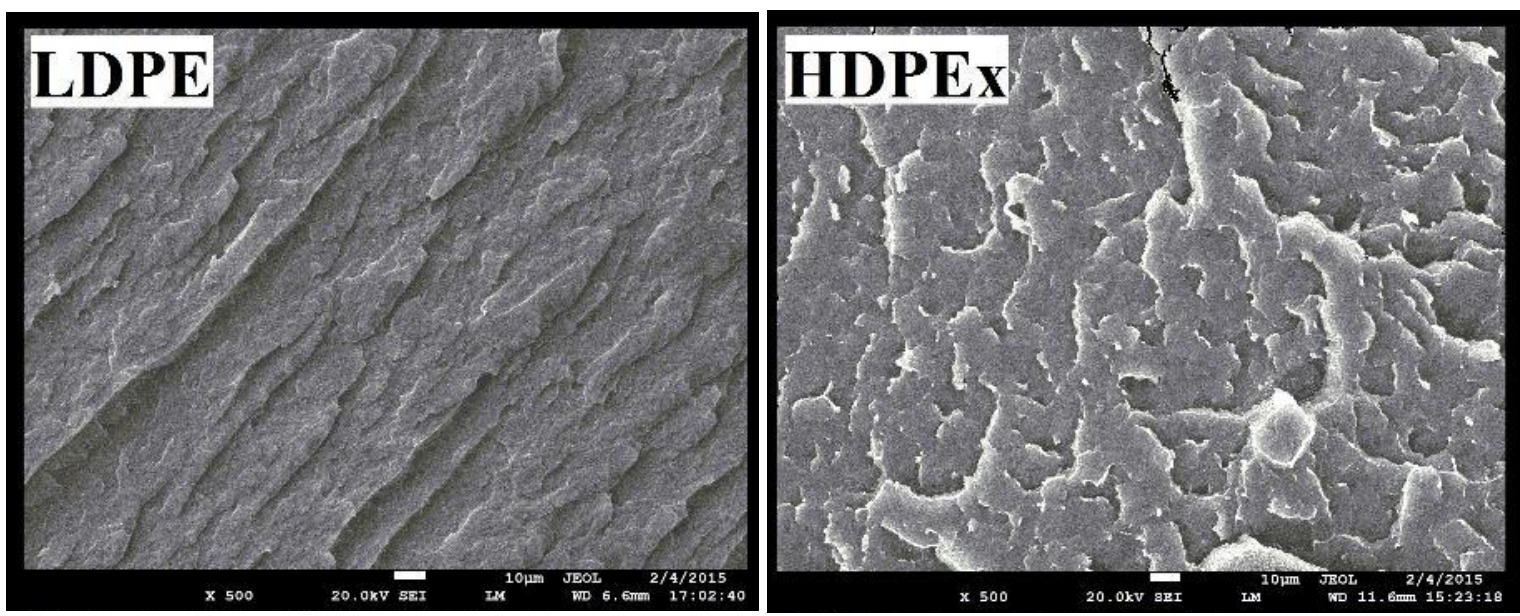

Figure 16. SEM-LDPE and HDPEx structure $(500 \times)$.

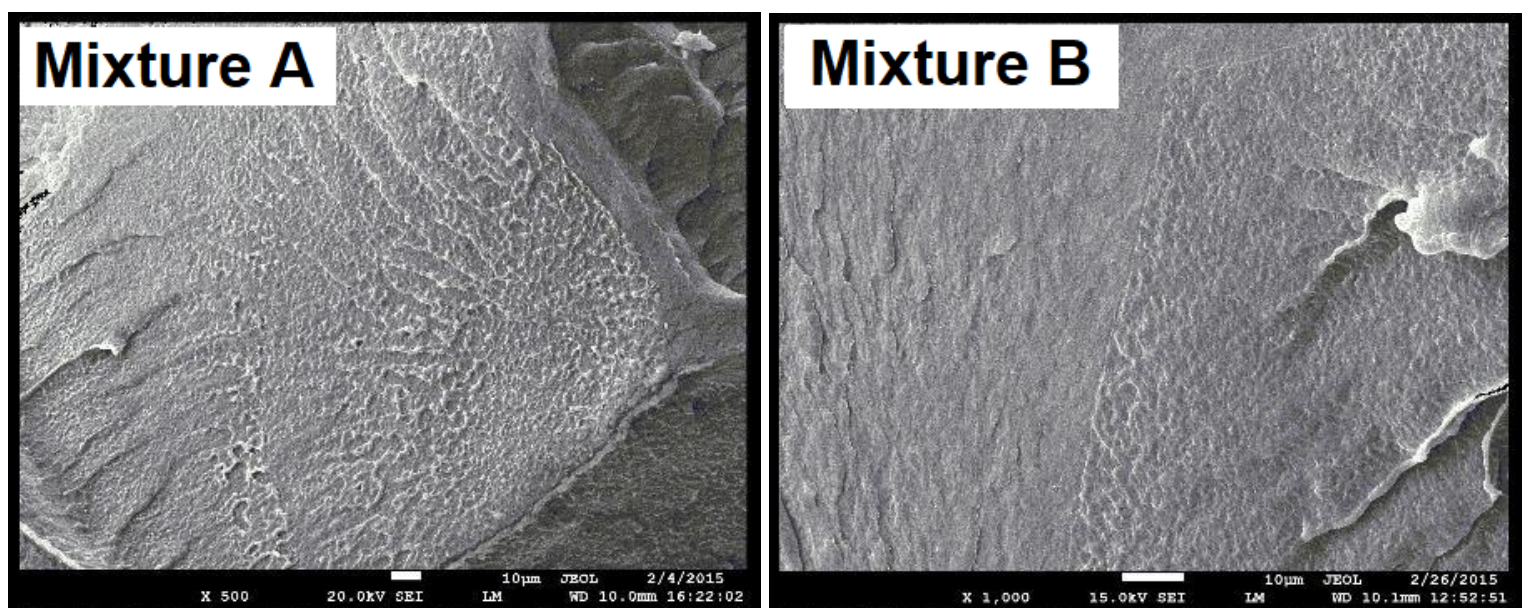

Figure 17. SEM-fracture surface structure of Mixtures A and B. 


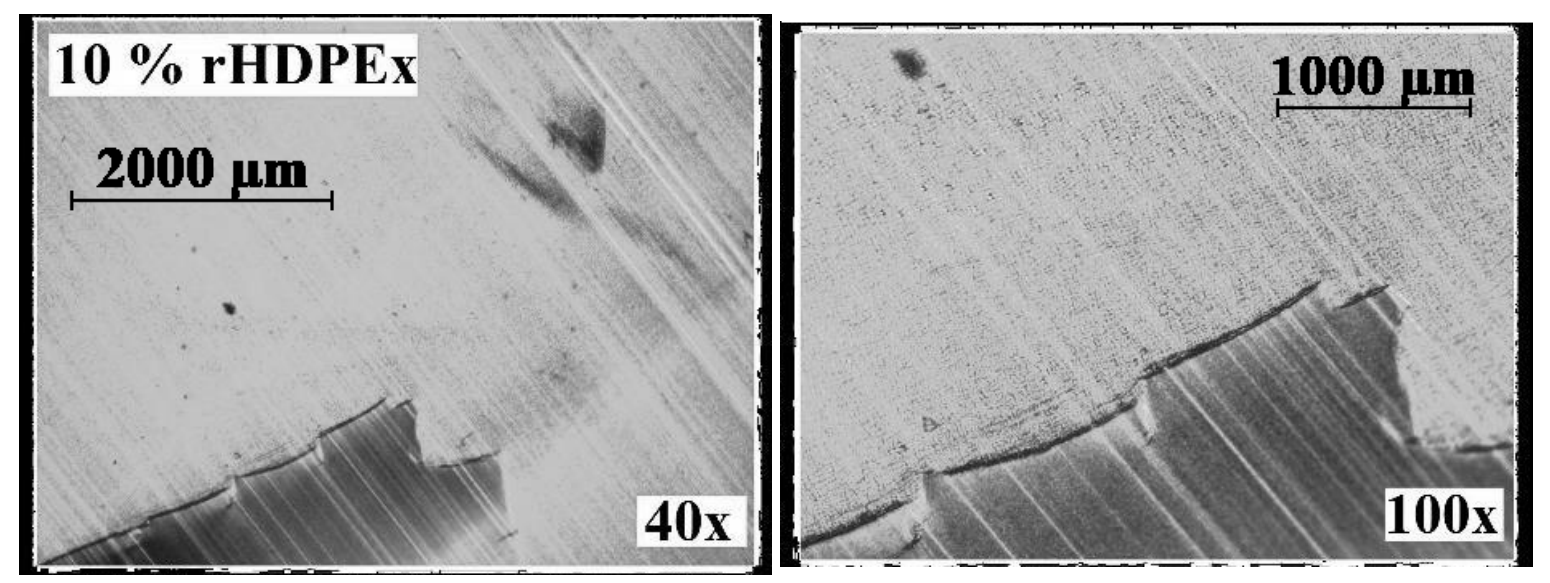

Figure 18. Microtome cuts of Mixture A.

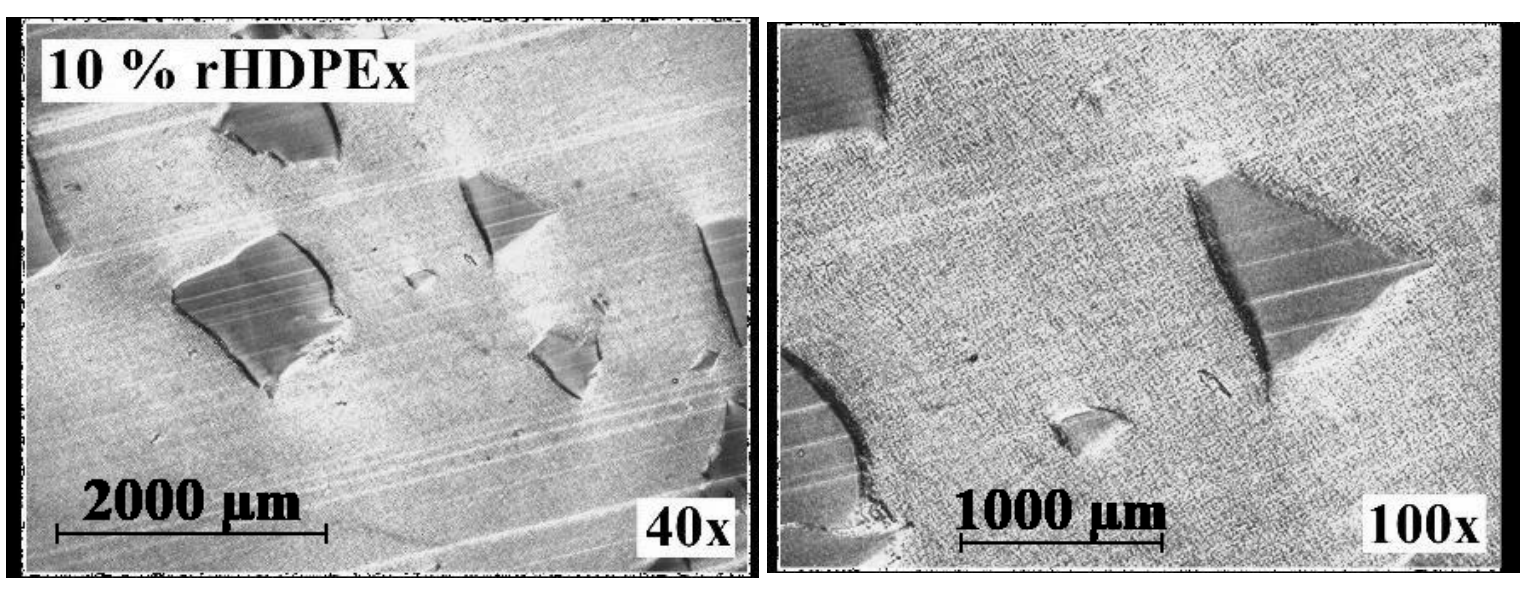

Figure 19. Microtome cuts of Mixture B.

\section{Conclusions}

The aim of this paper was to show the results obtained from the utilization of recycled irradiated High Density PolyEthylene (rHDPEx). Underfloor heating pipe waste, made from HDPEx, was used for this study. The idea of using this material as a filler was studied with the aim of investigating the influence of the filler on the mechanical properties and processability of the mixture. The results show that this technology, in few steps-such as cleaning (if necessary), crushing/grinding of the product from irradiated polymer, and the addition of grit or powder as a filler to the origin polymer matrix, in the concentration up to $60 \mathrm{wt}$. \%—could be very successfully implemented in the waste-processing field. The utilization of crushed/ground rHDPEx as a filler for virgin LDPE matrix seems to be the easiest-and most efficient way-to perform this form of waste processing. It is also possible to take further steps-e.g., the re-granulation of the prepared mixture-but this leads to a rise in production costs. This research paper offers answers to the problem of the re-utilization of irradiated high density polyethylene. Other materials are under research today, with the aim of making a general statement on the utilization of products made from irradiated polymers. The idea presented herein is very simple, and could be, without need for huge investments, used in practice to transform today's unused waste into the required raw material for the production of a huge amount of useful products.

Author Contributions: D.M., J.N., and M.O. designed and performed the experiments; K.T. and S.S. analysed the data; and M.M. and A.M. conceived and designed the experiments and wrote the paper.

Funding: This work was supported by the Czech Ministry of Industry and Trade in Program "Aplikace" No. CZ 01.1.02/0.0/0.0/16_084/0009949, by the European Regional Development Fund under the project CEBIA-Tech 
Instrumentation No. CZ.1.05/2.1.00/19.0376 and by the Ministry of Education, Youth and Sports of the Czech Republic within the National Sustainability Programme project No. LO1303 (MSMT-7778/2014)

Acknowledgments: Our great thanks belong to our colleague and co-worker, David Manas, for his long lasting cooperation and supervision of numerous academic diploma works and theses. David was a promising and highly regarded pedagogue and scientist; and a leading person in the research area presented in this article. He passed away unexpectedly in mid-September 2017, at the age of only 42 years. We were honoured to work with him. May his soul rest in peace.

Conflicts of Interest: The authors declare no conflict of interest.

\section{References}

1. Nikolić, M.A.; Gauthier, E.; Colwell, J.M.; Halley, P.; Bottle, S.E.; Laycock, B.; Truss, R. The challenges in lifetime prediction of oxodegradable polyolefin and biodegradable polymer films. Polym. Degrad. Stab. 2017, 145, 102-119. [CrossRef]

2. Laycock, B.; Nikolić, M.; Colwell, J.M.; Gauthier, E.; Halley, P.; Bottle, S.; George, G. Lifetime prediction of biodegradable polymers. Prog. Polym. Sci. 2017, 71, 144-189. [CrossRef]

3. Ignatyev, I.A.; Thielemans, W.; Vander Beke, B. Recycling of Polymers: A Review. ChemSusChem 2014, 7, 1579-1593. [CrossRef] [PubMed]

4. Hubo, S.; Leite, L.; Martins, C.; Ragaert, K. Evaluation of post-industrial and post-consumer polyolefin-based polymer waste streams for injection moulding. In Proceedings of the 6th Polymers \& Mould Innovations International Conference, Guimaraes, Portugal, 10-12 September 2014; pp. 201-206.

5. Ragaert, K.; Delva, L.; Geem, K.V. Mechanical and chemical recycling of solid plastic waste. Waste Manag. 2017, 69, 24-58. [CrossRef] [PubMed]

6. Oblak, P.; Gonzalez-Gutierrez, J.; Zupančič, B.; Aulova, A.; Emri, I. Processability and mechanical properties of extensively recycled high density polyethylene. Polym. Degrad. Stab. 2015, 114, 133-145. [CrossRef]

7. Brandrup, J. Recycling and Recovery of Plastics; Hanser Publishers: Munich, Germany, 1996.

8. Al-Salem, S.; Lettieri, P.; Baeyens, J. Recycling and recovery routes of plastic solid waste (PSW): A review. Waste Manag. 2009, 29, 2625-2643. [CrossRef] [PubMed]

9. Hopewell, J.; Dvorak, R.; Kosior, E. Plastics recycling: Challenges and opportunities. Philos. Trans. R. Soc. Lond. B Biol. Sci. 2009, 364, 2115-2126. [CrossRef] [PubMed]

10. Bajracharya, R.M.; Manalo, A.C.; Karunasena, W.; Lau, K.T. Characterisation of recycled mixed plastic solid wastes: Coupon and full-scale investigation. Waste Manag. 2016, 48, 72-80. [CrossRef] [PubMed]

11. Díaz, S.; Ortega, Z.; McCourt, M.; Kearns, M.P.; Benítez, A.N. Recycling of polymeric fraction of cable waste by rotational moulding. Waste Manag. 2018. [CrossRef] [PubMed]

12. Stenvall, E.; Tostar, S.; Boldizar, A.; Foreman, M.R.; Möller, K. An analysis of the composition and metal contamination of plastics from waste electrical and electronic equipment (WEEE). Waste Manag. 2013, 33, 915-922. [CrossRef] [PubMed]

13. Censori, M.; Marca, F.L.; Carvalho, M.T. Separation of plastics: The importance of kinetics knowledge in the evaluation of froth flotation. Waste Manag. 2016, 54, 39-43. [CrossRef] [PubMed]

14. Arvanitoyannis, I.S.; Bosnea, L.A. Recycling of polymeric materials used for food packaging: Current status and perspectives. Food Rev. Int. 2001, 17, 291-346. [CrossRef]

15. Rem, P.; Maio F.D.; Hu, B.; Houzeaux, G.; Baltes, L.; Tierean, M. Magnetic fluid equipment for sorting secondary polyolefins from waste. Environ. Eng. Manag. J. 2013, 12, 951-958.

16. Baričević, A.; Rukavina, M.J.; Pezer, M.; Štirmer, N. Influence of recycled tire polymer fibers on concrete properties. Cem. Concr. Compos. 2018, 91, 29-41. [CrossRef]

17. Stenvall, E.; Boldizar, A. Mechanical and Thermal Characterization of Melt-Filtered, Blended and Reprocessed Post-Consumer WEEE Thermoplastics. Recycling 2016, 1, 89-100. [CrossRef]

18. Puig-Arnavat, M.; Bruno, J.C.; Coronas, A. Review and analysis of biomass gasification models. Renew. Sustain. Energy Rev. 2010, 14, 2841-2851. [CrossRef]

19. Angyal, A.; Miskolczi, N.; Bartha, L. Petrochemical feedstock by thermal cracking of plastic waste. J. Anal. Appl. Pyrolysis 2007, 79, 409-414. [CrossRef]

20. Kumar, A.; Jones, D.D.; Hanna, M.A. Thermochemical Biomass Gasification: A Review of the Current Status of the Technology. Energies 2009, 2, 556-581. [CrossRef] 
21. Drobny, J.G. 9-Safety and Hygiene. In Ionizing Radiation and Polymers; Drobny, J.G., Ed.; Plastics Design Library, William Andrew Publishing: New York, NY, USA, 2013; pp. 237-243.

22. Rouif, S. Radiation cross-linked polymers: Recent developments and new applications. Nucl. Instrum. Methods Phys. Res. Sect. B 2005, 236, 68-72. [CrossRef]

23. Gehring, J. With radiation crosslinking of engineering plastics into the next millennium. Radiat. Phys. Chem. 2000, 57, 361-365. [CrossRef]

24. Navratil, J.; Manas, M.; Mizera, A.; Bednarik, M.; Stanek, M.; Danek, M. Recycling of irradiated high-density polyethylene. Radiat. Phys. Chem. 2015, 106, 68-72. [CrossRef]

25. Burillo, G.; Clough, R.L.; Czvikovszky, T.; Guven, O.; Moel, A.L.; Liu, W.; Singh, A.; Yang, J.; Zaharescu, T. Polymer recycling: Potential application of radiation technology. Radiat. Phys. Chem. 2002, 64, 41-51. [CrossRef]

26. Vasachar, R.; Bhajantri, R.F.; Dhola, P.S.; Sanjeev, G. Impact of electron-beam irradiation on free-volume related microstructural properties of PVA: NaBr polymer composites. Nucl. Instrum. Methods Phys. Res. Sect. B 2015, 342, 29-38.

27. Adem, E.; Avalos-Borja, M.; Carrillo, D.; Vazquez, M.; Sanchez, E.; Carreon, M.; Burillo, G. Crosslinking of recycled polyethylene by gamma and electron beam irradiation. Radiat. Phys. Chem. 1998, 52, 171-176.

28. Navratil, J.; Manas, M.; Stanek, M.; Manas, D.; Bednarik, M.; Mizera, A. Influence of Recycled Irradiated HDPE on Mechanical Behavior of LDPE/Hdpex Blends. In Advanced Materials, Structures and Mechanical Engineering; Trans Tech Publications: Stafa-Zurich, Switzerland, 2014; Volume 1025, pp. 265-269.

29. Navratil, J.; Manas, M.; Stanek, M.; Manas, D.; Ovsik, M.; Bednarik, M.; Mizera, A. Hardness and Micro-Indentation Hardness Comparison of Recycled Modified HDPE. Key Eng. Mater. 2014, 606, 217-220. [CrossRef]

30. Tokuda, S.; Horikawa, S.; Negishi, K.; Uesugi, K.; Hirukawa, H. Thermoplasticizing technology for the recycling of crosslinked polyethylene. Furukawa Rev. 2003, 23, 88-93.

31. sam Janajreh, I.; Alshrah, M. Remolding of Cross-Linked Polyethylene Cable Waste: Thermal and Mechanical Property Assessment. Int. J. Therm. Environ. Eng. 2013, 5, 191-198.

32. Qudaih, R.; Janajreh, I.; Vukusic, S. Recycling of Cross-linked Polyethylene Cable Waste via Particulate Infusion. In Advances in Sustainable Manufacturing; Springer: Berlin/Heidelberg, Germany, 2011; pp. 233-239.

33. International Organization for Standardization (ISO). Practice for Calibration of Routine Dosimetry Systems for Radiation Processing; Standard; International Organization for Standardization: Geneva, Switzerland, 2013.

34. ASTM International. Standard Test Method for Determining Gel Content in Crosslinked Ethylene Plastics Using Pressurized Liquid Extraction (Withdrawn 2015); Standard; ASTM International: West Conshohocken, PA, USA, 2009.

35. International Organization for Standardization (ISO). Plastics-Determination of Tensile Properties; Standard; International Organization for Standardization: Geneva, Switzerland, 2012.

36. Czech Office for Standards Metrology and Testing (UNMZ). CSN en ISO 1133-1-Plastics-Determination of the Melt Mass-Flow Rate (MFR) and Melt Volume-Flow Rate (MVR) of Thermoplastics-Part 1: Standard Method; Standard; Czech Office for Standards Metrology and Testing: Prague, Czech Republic, 2011.

37. Stanek, M.; Manas, D.; Manas, M. Stavebnicova Testovaci Vstrikovaci Forma; Uzitny vzor 23338; Industrial Property Office: Prague, Czech Republic, 2012.

38. International Organization for Standardization (ISO). Plastics and Ebonite-Determination of Indentation Hardness by Means of A Durometer (Shore Hardness); Standard; International Organization for Standardization: Geneva, Switzerland, 2003.

39. International Organization for Standardization (ISO). Metallic Materials_Instrumented Indentation Test for Hardness and Materials Parameters; Standard; International Organization for Standardization: Geneva, Switzerland, 2015.

40. International Organization for Standardization (ISO). Plastics-Determination of Charpy Impact Properties-Part 2: Instrumental Impact Test; Standard; International Organization for Standardization: Geneva, Switzerland, 1997.

(C) 2018 by the authors. Licensee MDPI, Basel, Switzerland. This article is an open access article distributed under the terms and conditions of the Creative Commons Attribution (CC BY) license (http:// creativecommons.org/licenses/by/4.0/). 